\title{
Low-cost filter media for removal of hydrogen sulphide from piggery biogas
}

\author{
A.G. Skerman ${ }^{a, *}$, S. Heubeck ${ }^{b}$, D.J. Batstone ${ }^{c}$, S. Tait ${ }^{c}$ \\ a Department of Agriculture and Fisheries (DAF), 203 Tor Street, P.O. Box 102, Toowoomba, Qld 4350, Australia \\ $\mathrm{b}$ National Institute of Water and Atmospheric Research (NIWA), Hamilton 3216, New Zealand \\ c Advanced Water Management Centre, University of Queensland, St Lucia, Qld 4072, Australia
}

\section{A R T I C L E I N F O}

\section{Article history:}

Received 15 April 2016

Received in revised form 25 August

2016

Accepted 1 November 2016

Available online 9 November 2016

\section{Keywords:}

Biogas

Hydrogen sulphide

Iron-oxide

Pig

Swine

Manure

\begin{abstract}
A B S T R A C T
The presence of elevated concentrations of hydrogen sulphide $\left(\mathrm{H}_{2} \mathrm{~S}\right)$ in piggery biogas is problematic due to its corrosiveness and toxicity. At small scale, the cost of using iron or carbon-based commercial filter media to remove $\mathrm{H}_{2} \mathrm{~S}$ can act as a barrier to the uptake of on-farm biogas technology. To identify cost-effective, alternative options, this study tested and compared $\mathrm{H}_{2} \mathrm{~S}$ removal by the commercial iron-oxide $\mathrm{H}_{2} \mathrm{~S}$ scavenger $\left(\mathrm{cg}_{5}\right)$ with the alternative solid media: granulated steel furnace slag (GSFS), red soil, compost, composted beef feedlot manure, granular activated carbon (GAC) and biochar. Experiments measured single-pass $\mathrm{H}_{2} \mathrm{~S}$ removal from a pre-humidified standard gas (2000 ppm $\mathrm{H}_{2} \mathrm{~S}$ in nitrogen) onto solid media contained in a cylindrical plastic column (DN $25 \mathrm{~mm}$, depth 110-147 mm). The commercial medium ( $\left.\mathrm{cg}_{5}\right)$ performed considerably better than the other media, achieving sulphur removal of $143 \mathrm{~g} \mathrm{~S} / \mathrm{kg}$ medium at breakthrough ( $>10 \mathrm{ppm}$ outlet $\mathrm{H}_{2} \mathrm{~S}$ ). A red soil was the most promising alternative medium ( $2-12 \mathrm{~g} \mathrm{~S} / \mathrm{kg}$ medium at breakthrough). The crystalline structure of the iron-oxide minerals appeared to strongly influence the $\mathrm{H}_{2} \mathrm{~S}$ removal capacity of the red soils, and pressure drop was generally high. Bulking with ground sugar cane mulch (SCM) was effective at reducing pressure drop. Interestingly, $\mathrm{H}_{2} \mathrm{~S}$ removal with red soil improved when the soil was regenerated by exposure to air, followed by reuse in the column. Overall, red soil may be a suitable low-cost option, especially for polishing biogas after initial biological $\mathrm{H}_{2} \mathrm{~S}$ removal.
\end{abstract}

Crown Copyright @ 2016 Published by Elsevier B.V. on behalf of Institution of Chemical Engineers. All rights reserved.

\section{Introduction}

In Australia, there has been increasing interest in on-farm biogas use in recent years, especially in the intensive livestock sector. The main drivers have been to reduce on-farm energy costs and greenhouse gas (GHG) emissions associated with manure treatment. Life Cycle Assessment (LCA) studies (Wiedemann et al., 2012) indicated that biogas capture and use could reduce total GHG emissions by $51-61 \%$ across the Australian pork supply chain. Also, electricity costs contribute an average of $2 \%$ to the total cost of production for Australian conventional piggeries (Willis, 2015), whereas on-farm biogas energy production at piggeries is often more than double the on-farm energy consumption (Skerman et al., 2015).
However, the concentrations of hydrogen sulphide $\left(\mathrm{H}_{2} \mathrm{~S}\right)$ in biogas which can be as high as 500-3000 ppm (Safley and Westerman, 1988; FNR, 2005; Heubeck and Craggs, 2010), can be a major obstacle to the uptake of biogas technology due to toxicity and corrosion concerns. For instance, the Safe Work Australia (2013) 8-h average and short term exposure limits for $\mathrm{H}_{2} \mathrm{~S}$ are 10 and $15 \mathrm{ppm}$, respectively. Also, $\mathrm{H}_{2} \mathrm{~S}$ in the presence of oxygen can form sulphur dioxide, which acidifies generator engine oil and, when further dissolved in condensed moisture, forms sulphuric or sulphurous acids that are highly corrosive to biogas-fired appliances and associated metallic fittings (Wiebe, 2014; Allan, 2012). $\mathrm{H}_{2} \mathrm{~S}$ concentrations less than $200 \mathrm{ppm}$ are generally recommended for most biogas-fired generator engines, and biogas boilers can tolerate $\mathrm{H}_{2} \mathrm{~S}$ up to $1000 \mathrm{ppm}$, depending on the materials of manufacture

* Corresponding author.

E-mail addresses:

d.batstone@awmc.uq.edu.au (D.J. Batstone), s.tait@uq.edu.au (S. Tait). http://dx.doi.org/10.1016/j.psep.2016.11.001

0957-5820/Crown Copyright @ 2016 Published by Elsevier B.V. on behalf of Institution of Chemical Engineers. All rights reserved. 
(Wellinger and Lindberg, 2005). As such, piggery biogas generally needs treatment to remove part or all of the $\mathrm{H}_{2} \mathrm{~S}$ prior to use on-farm.

At farm scale, $\mathrm{H}_{2} \mathrm{~S}$ is commonly removed by passing the raw biogas through packed columns of a porous, solid filter medium that absorbs and binds the $\mathrm{H}_{2} \mathrm{~S}$. The solid medium generally contains iron or zinc that reacts with $\mathrm{H}_{2} \mathrm{~S}$ to form sulphide precipitates, i.e. iron sulphide (Wellinger and Lindberg, 2005; Ryckebosch et al., 2011). A commonly applied commercial product is "iron sponge", which consists of iron-oxide-impregnated wood-chips, generally pine (Zicari, 2003; Abatzoglou and Boivin, 2009). In recent years, several commercial media have been offered as improved alternatives to iron sponge, to be used for $\mathrm{H}_{2} \mathrm{~S}$ removal across a range of industries (Zicari, 2003). Such commercial products have iron coatings on different supporting structures such as dried manure, ceramic beads, diatomaceous earth, or unspecified proprietary materials (Cherosky and Li, 2013), or consist of pelletised iron-oxide rich substrate, for example red mud, which is a waste product from aluminium production (Wellinger and Lindberg, 2005). Other biogas filter media are based on active carbon, often doped or impregnated with compounds such as sodium hydroxide $(\mathrm{NaOH})$, potassium hydroxide $(\mathrm{KOH})$, sodium bicarbonate $\left(\mathrm{NaHCO}_{3}\right)$ or potassium permanganate $\left(\mathrm{KMnO}_{4}\right)$, which combine physical and chemical absorption pathways (Wellinger and Lindberg, 2005; Siefers, 2010; Abatzoglou and Boivin, 2009). These commercial media are engineered to provide high specific surface area with a low overall pressure drop over the packed column, and together with a high content of active ingredient, provide high sulphide binding capacity.

As illustrated by the calculations and examples provided in Supplementary material, the cost of supplying and replacing commercial media can significantly impact on the economic feasibility of on-farm biogas use. We estimate that as much as $5 \%$ of the savings from biogas might be used on replacing spent filter media. This highlights a need to identify more cost-effective filter media to make on-farm biogas systems more economically attractive for uptake amongst Australia's rural sector.

Fortunately, the active compounds enabling $\mathrm{H}_{2} \mathrm{~S}$ removal seem to be relatively common in natural materials such as soils and even in some agricultural and industrial waste and by-products. Consequently, a range of other low-cost materials - such as biodegradable wastes - may also be useful for $\mathrm{H}_{2} \mathrm{~S}$ removal (Cherosky and Li, 2013). For instance, $\mathrm{H}_{2} \mathrm{~S}$ from coal derived natural gas has been effectively removed by iron-rich and zinc contaminated soils (Ko, 2008, 2011; Ko and Hsueh, 2012). Moreover, cow manure compost in biofilter columns has shown considerable potential for $\mathrm{H}_{2} \mathrm{~S}$ removal, albeit through oxidation as well as precipitation (Zicari, 2003). Similarly, a biofiltration packing material based on pig manure and sawdust has proven to be effective at degrading $\mathrm{H}_{2} \mathrm{~S}$ in gas streams (Elias et al., 2002). Trials have also been previously carried out on a variety of other media, including soil, peat, compost, sludge, pig manure/sawdust, wood bark, activated carbon, rock wool, lava rock, poly-propylene rings, calcium-alginate beads, fuyolite and ceramics (referenced in Zicari, 2003). These literature references suggest that $\mathrm{H}_{2} \mathrm{~S}$ removal can, at least in principle, be supported by many natural and waste materials.

Of concern to the performance and whole-of-life cost of ironoxide/hydroxide media, is the ability to regenerate the spent media by exposure to oxygen (air) which converts iron back into the reactive form (Wang, 2008). Over multiple cycles of use-regenerate-reuse, the medium is eventually filled with elemental sulphur and becomes spent, requiring replacement (Ryckebosch et al., 2011). However, the ability to regenerate substantially increases the whole-of-life capacity for $\mathrm{H}_{2} \mathrm{~S}$ removal and therefore greatly reduces associated costs. It is not known whether alternative solid media (such as iron-rich soils) would have significant regeneration capacity.

Overall, there is a need for more viable, low-cost, alternative media for $\mathrm{H}_{2} \mathrm{~S}$ removal from on-farm biogas. To identify cost-feasible options, the present study tested and compared $\mathrm{H}_{2} \mathrm{~S}$ removal by a commercial iron-based medium ( $\left.\mathrm{cg}_{5}\right)$ with low-cost alternative iron-based solid media (GSFS and red soil) and GAC, biochar, compost and composted beef feedlot manure. A study was also performed to assess whether one of the alternative media, namely iron-rich red soil, could be regenerated by exposure to air for reuse as a filter medium.

\section{Materials and methods}

Lab-scale experiments measured single-pass $\mathrm{H}_{2} \mathrm{~S}$ removal from a pre-humidified standard gas onto solid filter media contained in a cylindrical plastic column.

\subsection{Materials}

To simulate a typical piggery biogas, a cylinder containing 2000 ppm $\mathrm{H}_{2} \mathrm{~S}$ in high purity nitrogen was sourced from Encore Automation Pty Ltd. (Balcatta, WA) for use as the test gas. Nitrogen, rather than the main biogas components methane and carbon dioxide, was used as the carrier in the test gas for safety reasons and was not expected to influence the test results (Wang, 2008). Deionised water was used to humidify the test gas mixture. Oxygen $\left(\mathrm{O}_{2}\right)$, sourced from BOC Ltd., Toowoomba, was used to dilute the test gas prior to measurement by an electro-chemical sensor. Since $\mathrm{H}_{2} \mathrm{~S}$ is toxic and potentially lethal, appropriate control strategies were in place to manage the associated health risks.

The following iron and carbon-based media were tested in the experiments: $\mathrm{cg}_{5}$ iron-oxide $\mathrm{H}_{2} \mathrm{~S}$ scavenger material (Shanxi Clean Company of Catalysis and Purification Technologies Development), GSFS ( $<5 \mathrm{~mm}$, Cement Australia, Darra, Qld), GSFS (M21—coarse, Wagners, Toowoomba, Qld), naturally-occurring red soil excavated from just below the soil surface (A horizon) at 203 Tor Street, Toowoomba, Qld (S 27 $32^{\prime} 05^{\prime \prime}$, E $151^{\circ} 55^{\prime} 46^{\prime \prime}$ ), naturally-occurring red soil excavated from a road cutting (B horizon) at Ravensbourne, Qld (S $27^{\circ} 22^{\prime} 18^{\prime \prime}$, E $152^{\circ} 10^{\prime} 05^{\prime \prime}$ ), GAC (Calgon BPL 4x10), compost (Naturegrow, Amgrow Pty Ltd.), composted beef feedlot manure (Kerwee feedlot, Jondaryan, Qld) and biochar (Green waste 550, Pacific Pyrolysis Pty Ltd., Somersby, NSW). The red soil, compost, composted beef feedlot manure and biochar samples were prepared for testing by sieving through a $2 \mathrm{~mm}$ sieve to remove coarse fragments. A sieved sample of the Ravensbourne red soil (at $500 \mu \mathrm{m}$ ) was also tested as a finer textured product. Sugar cane mulch (SCM, Rocky Point Mulching, Woongoolba, Qld), serving as a bulking agent to reduce pressure drop with tests on soil, was mechanically ground using a Retsch SM 100 Cutting Mill and mixed with the red soil in proportions $20 \% \mathrm{v} / \mathrm{v}$ SCM or $40 \% \mathrm{v} / \mathrm{v}$ SCM.

The analytical methods described below were used to determine the Total solids (TS) and Volatile solids (VS) content, bulk density, particle density and porosity values (including interstitial voids), and aluminium ( $\mathrm{Al}$ ), iron ( $\mathrm{Fe}$ ), phosphorus (P) and sulphur (S) elemental concentrations, for each test medium.

\subsection{Apparatus}

Fig. 1 provides a schematic of the experimental apparatus. The outlet pressures on the cylinders of test gas and $\mathrm{O}_{2}$ were set at approximately $200 \mathrm{kPa}$ and the gas flow was controlled by Alicat MCS-1SLPM-D/5M and MC-100SCCM-DX$0.25 \mathrm{VCR} / 5 \mathrm{M}$ mass flow controllers (Alicat Scientific, Tucson, AZ 85743, USA), respectively. To emulate raw piggery biogas which is usually saturated with moisture, the test gas was pre-humidified by bubbling through a $150 \mathrm{~mm}$ height of deionised water and the resulting relative humidity of the gas was confirmed to be $>95 \%$ using a humidity sensor 


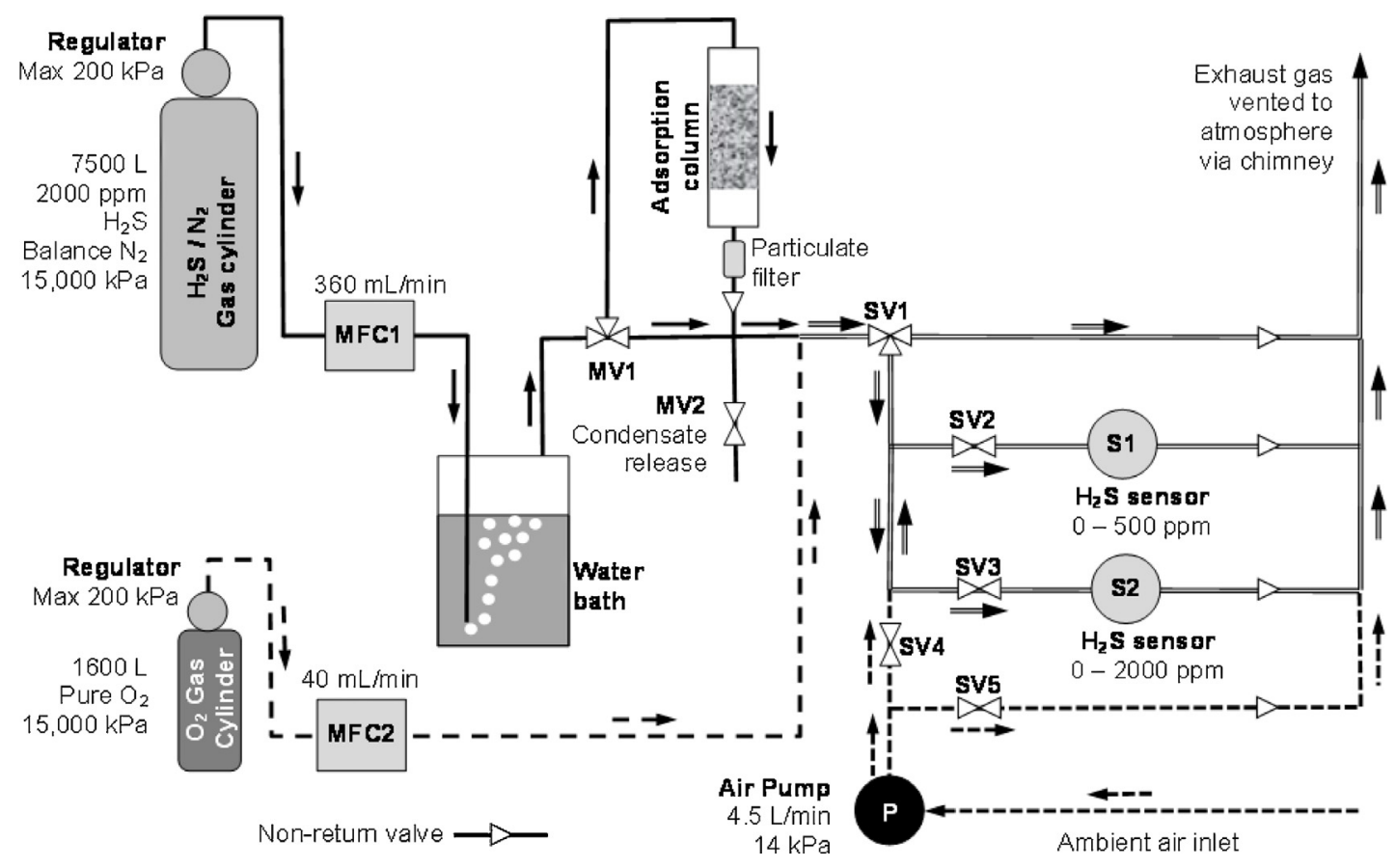

Fig. 1 - Schematic drawing of the apparatus used during the hydrogen sulphide sorption experiments.

(HOBO ${ }^{\circledR}$ Pro v2 U23-002). A cylindrical test column was fabricated from PVC pressure pipe (nominal diameter DN $25 \mathrm{~mm}$, internal diameter $29.8 \mathrm{~mm}$, PN 12-1.2 MPa maximum working pressure) with Polythene end-cap fittings and a stainless steel mesh base-plate to support the solid test medium. A 3-way manual valve (MV1) was used to direct the test gas through either the test column or a bypass line. The gas exiting the column passed through a particulate filter (Swagelok SS-4F-2) to protect the downstream $\mathrm{H}_{2} \mathrm{~S}$ sensors. Oxygen was mixed with the test gas using the MFCs noted above at a volumetric proportion of 1:9, based on the sensor manufacturer's recommendations, before being directed by electrical solenoid valves (SMC VDW21-6G-2-01-G) to one of two $\mathrm{H}_{2} \mathrm{~S}$ sensors (Alphasense H2S-BE, Great Notley, CM77 7AA, UK) or to an external chimney. The solenoid valves were activated by solid-state relays directed by a HYTEK iUSBDA6-U120816 data acquisition module (HYTEK Automation Inc), which was controlled using LabVIEW Base Development System software (National Instruments Australia).

The measurement ranges of the sensors were $0-500 \mathrm{ppm}$ $\mathrm{H}_{2} \mathrm{~S}$ (S1) and 0-2000 ppm $\mathrm{H}_{2} \mathrm{~S}$ (S2). The sensors were fitted with digital transmitter boards producing 4-20 mA outputs which were converted to $0.48-2.40 \mathrm{~V}$ signals using $120 \Omega$ resistors installed in parallel with each sensor. To meet a manufacturer's requirement for minimum gas flow velocity across the sensor, the entire test gas flow was directed to only one of the two sensors depending on the relevant measurement range. To prolong the operating life of the sensors, a domestic aquarium aeration pump (Sera air $275 \mathrm{R}$ plus air pump, $4.5 \mathrm{~L} / \mathrm{min}$, $\geq 14 \mathrm{kPa}$ ) was used to purge the sensors with ambient air between measurement events. The durations of sampling and purging times, the sensor data logging frequency and the voltage output at which flow was to be switched from sensor S1 to $\mathrm{S} 2$, were nominated in a PC user interface. All the components of the test apparatus were connected with perfluoroalkoxy (PFA) tubing and Swagelok ${ }^{\circledR} 1 / 4$ in. $(6.35 \mathrm{~mm})$ OD 316 stainless steel tube fittings.

\subsection{Batch $\mathrm{H}_{2} \mathrm{~S}$ removal studies}

The various media were added directly to the test column. As outlined in Table 2, the media masses, volumes, depths and test gas residence times varied due to bulk density variations between the different media (Table 2); however, column geometries were maintained within the recommended range, having depth to diameter ratios of 3:1 to 6:1 (ACP Technologies Inc., 2012) in all cases. After connecting the column to the test rig, the $\mathrm{H}_{2} \mathrm{~S}$ in $\mathrm{N}_{2}$ and $\mathrm{O}_{2}$ mass flow controllers were set at flow rates of 360 and $40 \mathrm{~mL} / \mathrm{min}$, respectively, with gas flow initially by-passing the test column and sensors, and discharging via the chimney. At the commencement of a test, the gas flow was redirected to the test column and the automatic test sequence was initiated using the LabVIEW software. The superficial flow velocity through the test column was $0.52 \mathrm{~m} / \mathrm{min}$, resulting in a medium residence time ranging from 15 to $17 \mathrm{~s}$ (depending on bed depth). The operating sequence alternated between five minutes of purging, where the gas flow from the column was directed to the chimney and the sensors were purged with air, followed by five minutes of sampling/measurement cycles, where flow from the column was directed to one of the sensors. This purge/sampling sequence was repeated until the measured $\mathrm{H}_{2} \mathrm{~S}$ concentration at the sensor approached $1800 \mathrm{ppm}$, indicating that the test medium was approaching saturation. During the test sequence, the lower-range sensor (S1) was protected from exposure to $\mathrm{H}_{2} \mathrm{~S}>500 \mathrm{ppm}$ by diverting gas flow to the higher-range sensor (S2) when $\mathrm{H}_{2} \mathrm{~S}$ concentrations exceeded $300 \mathrm{ppm}$.

Throughout the test sequence, the voltage output from the data acquisition module was recorded at $10 \mathrm{~s}$ intervals. Calibration curves were used to convert the sensor signals into $\mathrm{H}_{2} \mathrm{~S}$ concentrations at the outlet of the test column. These 
measured concentrations were plotted over time to produce breakthrough curves. Generalised logistic curves (Eq. (1)) were fitted to the data, using the function lsqcurvefit in Matlab R2013b:

$C(t)=L+\frac{U}{\left(1+Q \cdot e^{-B(t-M)}\right)^{1 / Q}}$

where $C(t)$ is the column outlet $\mathrm{H}_{2} \mathrm{~S}$ concentration (ppm) at time, $t(h), L$ is the lower asymptote $(0 \mathrm{ppm}), U$ is the upper asymptote $(2000 \mathrm{ppm}), B$ is the growth rate and $Q$ and $M$ are empirical fit parameters. This therefore contains 3 contestable parameters. The logistic curves allowed consistent interpolation over the entire breakthrough curve and identification of consistent breakthrough points. In some cases, the measured data exhibited two distinctly different responses over the test period. In such cases, two different logistic curves were added (Eq. (2)) to fit the entire test dataset.

$C(t)=L_{1}+\frac{U_{1}}{1+e^{-B_{1}\left(\ln (t)-M_{1}\right)}}+L_{2}+\frac{U_{2}}{1+e^{-B_{2}\left(\ln (t)-M_{2}\right)}}$

where $\mathrm{C}(\mathrm{t})$ is the measured $\mathrm{H}_{2} \mathrm{~S}$ concentration (ppm) at the column outlet at time $t(h), L_{1}$ and $L_{2}$ are lower asymptotes $(0 \mathrm{ppm})$, $U_{1}$ and $U_{2}$ are upper asymptotes, $B_{1}$ and $B_{2}$ are growth rates and $M_{1}$ and $M_{2}$ are empirical fit parameters. This therefore contains 5 contestable parameters.

The following four time events on the breakthrough curves were recorded, because they were of particular interest from an application perspective:

(i) $\mathrm{T}_{10}$ : the first occurrence of $\mathrm{H}_{2} \mathrm{~S}>10 \mathrm{ppm}$, approximating the breakthrough time, and representing the Safe Work Australia (2013) 8-h average exposure limit;

(ii) $\mathrm{T}_{200}$ : the first occurrence of $\mathrm{H}_{2} \mathrm{~S}>200 \mathrm{ppm}$, a common upper limit for internal combustion engine generators (Wellinger and Lindberg, 2005);

(iii) $\mathrm{T}_{1000}$ : the first occurrence of $\mathrm{H}_{2} \mathrm{~S}>1000 \mathrm{ppm}$, a common upper limit for boilers burning biogas (Wellinger and Lindberg, 2005); and

(iv) $\mathrm{T}_{1950}$ : the first occurrence of $\mathrm{H}_{2} \mathrm{~S}>1950 \mathrm{ppm}$, approximating saturation i.e. when $\mathrm{H}_{2} \mathrm{~S}$ concentration is the same at the inlet and outlet of the test column. Note that the $\mathrm{T}_{1950}$ value is indicative only, as most experiments were not run to saturation and hence it is model prediction only (empirical models have very limited predictive capability).

Model prediction curves including confidence intervals were generated using the Matlab function nlpredci using the jacobian generated by lsqcurvefit. This was then used to determine values including $95 \%$ confidence intervals for $\mathrm{T}_{10}-\mathrm{T}_{1950}$ from model and upper and lower confidence arrays using the Microsoft Excel Lookup function. Matlab functions and data sets are supplied in Supplementary materials.

For a subset of replicate tests, average results were calculated along with 95\% confidence limits. An Analysis of Variance (ANOVA) was performed to assess the variance between treatments $\left(\mathrm{H}_{2} \mathrm{~S}\right.$ concentrations) and the residual variances and a repeatability coefficient was calculated.

\subsection{Pressure drop experiments}

The pressure drop through the $\mathrm{cg}_{5}$ and red soil (Tor St, Toowoomba) media was assessed by passing a range of flowrates of high-purity $\mathrm{N}_{2}$ gas through approximately $100 \mathrm{~mL}$ of each medium (for a consistent bed depth) housed in the test column (Fig. 1). In an attempt to reduce pressure drop associated with the use of red soil, further pressure drop measurements were performed on red soil mixed with ground SCM as a bulking agent (red soil + SCM) at $20 \%$ and $40 \%$ (by volume). The gas flowrates were regulated using an Alicat MC-5SLPM-D-DB15/5M mass flow controller and the pressure drop was measured between tapping points directly upstream and downstream of the test column, using a TSI Model 8705 DP-CALC ${ }^{\mathrm{TM}}$ micro-manometer. The experimental results were used to derive graphical plots of the pressure drop per unit depth of medium vs. flow velocity, for comparison with values calculated using the Ergun equation (Eq. (3), Ergun, 1952) for the red soil and red soil + SCM media.

$\frac{\Delta P}{H}=150 \frac{\mu U(1-\varepsilon)^{2}}{\bar{x}_{S V}^{2} \varepsilon^{3}}+1.75 \frac{\rho_{f} U^{2}(1-\varepsilon)}{\bar{x}_{S V} \varepsilon^{3}}$

where $\Delta P$ is the measured pressure drop $(\mathrm{Pa}), \mathrm{H}$ is the bed depth $(\mathrm{m}), \mu$ is the gas dynamic viscosity $\left(1.76 \times 10^{-5} \mathrm{Pas}\right.$ at $20^{\circ} \mathrm{C}$, interpolated from Haynes, 2016), $U$ is the superficial gas velocity $(\mathrm{m} / \mathrm{s}), \varepsilon$ is the bed void fraction, $\bar{x}_{S V}$ is the surface-volume mean diameter of the packed bed particles (the mean diameter of a sphere that has the same surface area to volume ratio as the test media particles, $\mathrm{m}$ ) and $\rho_{f}$ is the gas density $\left(1.165 \mathrm{~kg} / \mathrm{m}^{3}\right.$ at $20^{\circ} \mathrm{C}$, interpolated from Haynes, 2016$)$. The value of the surface-volume mean diameter for the cg5 medium was estimated by first measuring the diameters and lengths of twenty randomly selected cg5 pellets, which were generally cylindrically-shaped, using digital Vernier callipers. The mean diameters of spheres having the same surface area to volume ratio as the cg5 pellets were calculated from the diameters and lengths. Because the red soil had a large range of particle diameters, from $2 \mathrm{~mm}$ down to very fine clay particles, and similarly, the ground SCM also had a large range of stalk diameters and lengths, it was considered impractical to attempt to measure particle diameters for the red soil and redsoil + SCM media, for use in the Ergun equation. Consequently, the values of the surface-volume mean diameters for the red soil and red soil + SCM particles were estimated using the Microsoft Excel ${ }^{\circledR}$ solver function, by minimising the sum of the squares of the differences between the measured values and the values calculated using the Ergun equation. Linear regression analyses were performed on the measured vs. predicted data plots and simultaneous F-tests for slope $=1$ and intercept $=0$ were carried out.

\subsection{Media regeneration studies}

A separate test examined the ability to regenerate a low-cost iron-rich medium by exposure to air. For this, a $\mathrm{H}_{2} \mathrm{~S}$ removal test was first performed on a sample of Tor St red soil as described in Section 2.3. Following the test, the soil sample was removed from the column and spread in a thin layer across the base of a shallow Pyrex dish to promote exposure to ambient air over a period of one week. After this, the sample was loaded back into the test column and another $\mathrm{H}_{2} \mathrm{~S}$ removal test was performed, again as described in Section 2.3. This use-regenerate-reuse was repeated three times on the same sample (a total of four uses). 


\subsection{Analytical methods}

The TS concentrations of the media were measured in triplicate using the methods recommended by Greenberg et al. (1992). Bulk density was measured in triplicate by a simplified tapping density technique. For this, a known mass of test medium was placed in a $100 \mathrm{~mL}$ measuring cylinder which was then manually tapped on a laboratory bench until no further settlement of the medium was observed (typically within $30 \mathrm{~s}$ ). At this point the final tapped volume was recorded to calculate the associated density. The particle densities of each of the media (pre-dried at $80^{\circ} \mathrm{C}$ and ground into a fine powder using a mortar and pestle) were measured using an AccuPyc II 1340, Helium Pycnometer. Each sample was purged with helium 20 times in the pycnometer to remove air and moisture. The particle density was then determined as an average of 10 measurements on each individual sample. The porosity of each medium was then calculated from the bulk density and particle density values [Porosity $(\%)=(1-$ (bulk density $/$ particle density) $\times 100$ ]. The elemental concentrations of $\mathrm{Al}$, Fe and $\mathrm{S}$ were determined by inductively coupled plasma atomic emission spectroscopy (ICP-OES). For this, the media samples were digested with a 6:2:2 ratio of $\mathrm{HCl}, \mathrm{HNO}_{3}$ and $\mathrm{HF}$ using a Milestone Ethos-1 microwave digester, prior to analysis using a Varian Vista Pro ICP-OES instrument.

\section{Results and discussion}

\subsection{Media properties}

Table 1 summarises characteristics of the various tested media. The commercial medium $\mathrm{cg}_{5}$ had the highest iron content (a proposed active ingredient). The red soils and GSFS (fine fraction) also had high iron contents. The carbon-based media (with low iron contents) had relatively high porosities in comparison to the other tested media (except $\mathrm{cg}_{5}$ ). Higher porosities would likely offer larger contact areas between the medium and $\mathrm{H}_{2} \mathrm{~S}$, and thus the high porosity of $\mathrm{cg}_{5}$ reflects the engineered nature of this commercial medium.

The two red soils tested in this experiment were both classified as krasnozems (Great Soil Group, Stace et al., 1968) or red ferrosols (Australian Soil Classification, Isbell, 1996). By definition, ferrosols have free iron-oxide contents greater than $5 \%$ Fe in the fine earth fraction $(<2 \mathrm{~mm}$ ) of the B2 horizon (Isbell, 1996). The iron contents determined by the ICP analyses for the samples of the Tor Street and Ravensbourne soils passing the $2 \mathrm{~mm}$ sieve were similar, at $14.1-15.5 \%(\mathrm{w} / \mathrm{w})$, respectively; however, the Ravensbourne red soil was a slightly brighter red colour compared with the Tor Street red soil. These colour differences could reflect different crystalline structures of the iron-oxide minerals present in the two soils (Schwertmann and Cornell, 2000). The largest proportion of soil total iron is in the form of oxide minerals such as hematite, goethite, lepidocrocite and ferrihydrite (Loeppert and Inskeep, 1996). The morphology of the two soils was also expected to be influenced by the degree of weathering. In this regard, the Ravensbourne red soil was likely to be a more mature, more deeply weathered soil, containing more strongly crystalline iron-oxide minerals which would be less reactive compared to weakly crystalline amorphous iron-oxide minerals found in the younger Tor St red soil. Ko (2008) found that the S sorption capacities of various oxisol (USDA soil taxonomy) soils was strongly correlated with the amounts of dithionite-citrate-bicarbonate (DCB) (a)

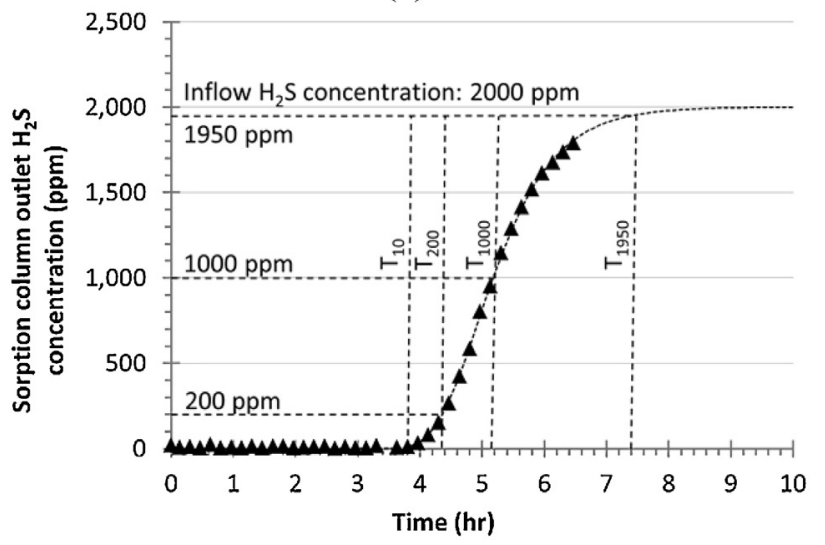

(b)

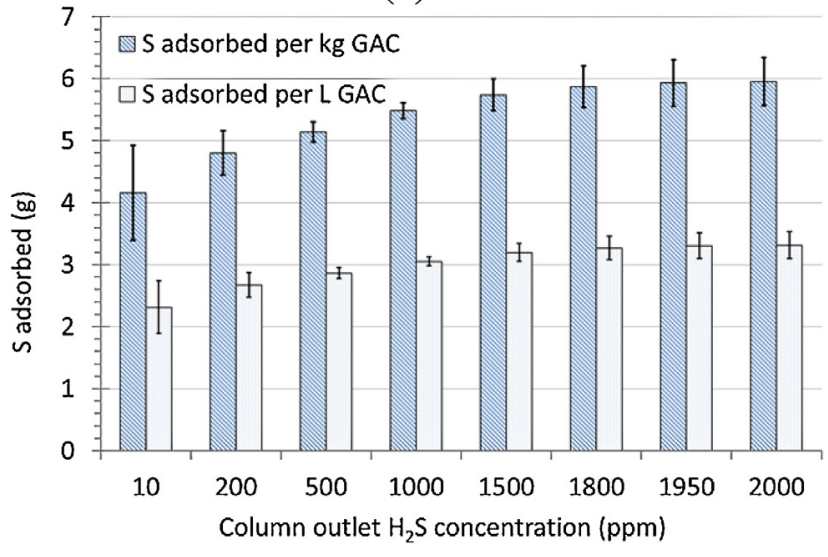

Fig. 2 - Experimental data from the $\mathrm{H}_{2} \mathrm{~S}$ removal tests. (a) A typical breakthrough curve (in this case for GAC) with the key times of interest also indicated $\left(\mathrm{T}_{10}\right.$ at breakthrough, $\mathrm{H}_{2} \mathrm{~S} \approx 10 \mathrm{ppm} ; \mathrm{T}_{200}, \mathrm{H}_{2} \mathrm{~S}=200 \mathrm{ppm} ; \mathrm{T}_{1000}, \mathrm{H}_{2} \mathrm{~S}=1000$ ppm; $\mathrm{T}_{1950}$ at saturation, $\left.\mathrm{H}_{2} \mathrm{~S}=1950 \mathrm{ppm}\right)$. The dashed line is a fit of Eq. (1). (b) Results from a reproducibility analysis on GAC showing mean values for sulphur removal capacity together with error bars estimated at the $95 \%$ confidence level.

extractable iron-oxides in the soils, indicating an effect of availability of iron on the reactivity with sulphide.

\subsection{Media performance/capacity}

Fig. 2a presents typical data from a $\mathrm{H}_{2} \mathrm{~S}$ removal test (a breakthrough curve, in this case for GAC 2) and indicates the four times $\left(\mathrm{T}_{10}, \mathrm{~T}_{200}, \mathrm{~T}_{1000}\right.$ and $\left.\mathrm{T}_{1950}\right)$ that were of particular practical interest in characterising the tested media (Section 2.3). Calculations determined the corresponding masses of sulphur removed from the biogas at each of these times (Table 2). The cumulative amounts of sulphur removed at $\mathrm{T}_{200}$ and $\mathrm{T}_{1000}$ are probably of greatest practical importance, because these correspond to the typical upper operating limits of internal combustion engines and boilers, respectively (Wellinger and Lindberg, 2005). Fig. $2 b$ presents data for a repeatability analysis performed on three separate samples of GAC, giving average values for sulphur removal capacity together with errors estimated at the $95 \%$ confidence limit. The repeatability coefficient was found to be 0.98 , indicating that the experimental results were reproducible. Fig. 3 presents breakthrough curves for various tested media (measured data together with fitted lines using Eq. (2)). Table 2 also presents the corresponding masses of sulphur removed (the capacity). 
Table 1 - Selected test media properties (mean values \pm error as $95 \%$ confidence interval in mean).

\begin{tabular}{|c|c|c|c|c|c|c|c|}
\hline Medium & TS (\% mass) & $\begin{array}{l}\text { Bulk density } \\
(\mathrm{g} / \mathrm{mL})\end{array}$ & $\begin{array}{l}\text { Particle density } \\
(\mathrm{g} / \mathrm{mL})\end{array}$ & Porosity (\%) ${ }^{c}$ & Fe (\% dry mass) & $\mathrm{Al}$ (\% dry mass) & $\mathrm{S}$ (\% dry mass \\
\hline \multicolumn{8}{|l|}{ Iron-based media } \\
\hline $\mathrm{cg}_{5}$ & $95.61 \pm 0.07$ & $0.699 \pm 0.024$ & $2.885 \pm 0.002$ & 75.8 & 20.32 & 0.12 & 5.61 \\
\hline GSFS (<5 mm) & $99.02 \pm 0.02$ & $2.122 \pm 0.111$ & $3.289 \pm 0.002$ & 35.5 & 16.22 & 2.58 & 0.14 \\
\hline GSFS (M21-coarse) & $99.93 \pm 0.02$ & $1.332 \pm 0.065$ & $2.719 \pm 0.001$ & 51.0 & 0.07 & 0.64 & 0.94 \\
\hline Red soil ${ }^{\mathrm{a}}$ Tor St & $87.29 \pm 0.08$ & $1.110 \pm 0.055$ & $2.701 \pm 0.001$ & 58.9 & $14.07 \pm 0.10$ & $5.61 \pm 0.12$ & $0.05 \pm 0.00$ \\
\hline Red soil ${ }^{\mathrm{a}}$ Ravensbourne & $82.90 \pm 0.13$ & $1.257 \pm 0.010$ & $2.764 \pm 0.001$ & 54.5 & 15.54 & 6.10 & 0.09 \\
\hline Red soil ${ }^{\mathrm{b}}$ Ravensbourne & $84.04 \pm 0.96$ & $1.256 \pm 0.033$ & $2.771 \pm 0.001$ & 54.7 & 16.29 & 5.69 & 0.11 \\
\hline \multicolumn{8}{|l|}{ Carbon-based media } \\
\hline GAC & $93.02 \pm 0.19$ & $0.557 \pm 0.002$ & $2.138 \pm 0.155$ & 73.9 & 0.18 & 0.46 & 1.06 \\
\hline Compost $^{\mathrm{a}}$ & $66.09 \pm 0.13$ & $0.597 \pm 0.014$ & $2.023 \pm 0.001$ & 70.5 & 2.25 & 2.21 & 0.66 \\
\hline Composted manure $^{a}$ & $64.38 \pm 0.64$ & $0.738 \pm 0.013$ & $1.871 \pm 0.002$ & 60.6 & 2.01 & 0.55 & 1.31 \\
\hline Biochar $^{a}$ & $90.21 \pm 0.32$ & $0.208 \pm 0.007$ & $1.664 \pm 0.027$ & 87.5 & 0.20 & 0.14 & 0.06 \\
\hline $\begin{array}{l}\text { a } \text { Samples prepared by s } \\
\text { b } \text { Sample prepared by si } \\
\text { c } \text { Porosity }(\%)=(1-\text { bulk }\end{array}$ & $\begin{array}{l}\text { eving at } 2 \mathrm{~mm} \text {. } \\
\text { ving at } 500 \mu \mathrm{m}\end{array}$ & nsity)) × 100 & & & & & \\
\hline
\end{tabular}

The $\mathrm{H}_{2} \mathrm{~S}$ removal capacity of the $\mathrm{cg}_{5}$ pellets was vastly superior compared to all of the other tested media (Table 2). The extrapolated $\mathrm{H}_{2} \mathrm{~S}$ removal capacity at saturation $(260 \mathrm{~g} \mathrm{~S} / \mathrm{kg}$ medium) agreed well with the supplier's claimed performance (250 g S/kg medium, ACP Technologies Inc., 2012). However, it was unclear whether the supplier's claimed performance corresponded to complete saturation or to breakthrough. The measured $\mathrm{H}_{2} \mathrm{~S}$ removal capacity at breakthrough for $\mathrm{cg}_{5}$ (143 g S/kg medium) also agreed well with that reported elsewhere for a similar material called $\mathrm{cg}_{4}$ (Wang et al., 2008; $141 \mathrm{~g} \mathrm{~S} / \mathrm{kg}$ medium). The high performance of $\mathrm{cg}_{5}$ was

Table 2 - Data for masses of sulphur removed (means $\pm 95 \%$ confidence intervals), corresponding to times of interest, including $\mathrm{T}_{10}$ (breakthrough $\mathrm{H}_{2} \mathrm{~S}>10 \mathrm{ppm}$ ), $\mathrm{T}_{200}$ (when $\mathrm{H}_{2} \mathrm{~S}=200 \mathrm{ppm}$ ), $\mathrm{T}_{1000}$ (when $\mathrm{H}_{2} \mathrm{~S}=1000 \mathrm{ppm}$ ) and $\mathrm{T}_{1950}$

\section{( $\approx$ saturation)}

Test medium [mass (g), volume Outlet $\mathrm{H}_{2} \mathrm{~S}$ conc Elution time $(\mathrm{h})^{\mathrm{b}}$ $(\mathrm{mL})$, depth $(\mathrm{mm})$, res time $(\mathrm{s})] \quad(\mathrm{ppm})$

\begin{tabular}{|c|c|c|c|c|c|}
\hline \multicolumn{2}{|c|}{ 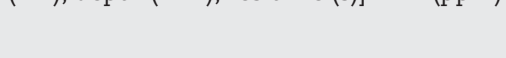 } & & (g S/kg Fe) & (g S/kg med) & (g S/L med) \\
\hline $\mathrm{cg}_{5}[71.2 \mathrm{~g}, 101.9 \mathrm{~mL}$ & 10 & $177 \pm 1$ & $737 \pm 0$ & $143 \pm 0$ & $100 \pm 0$ \\
\hline \multirow{3}{*}{$147.0 \mathrm{~mm}, 17.0 \mathrm{~s}]$} & 200 & $237 \pm 0$ & $976 \pm 0$ & $190 \pm 0$ & $132 \pm 0$ \\
\hline & 1000 & $312 \pm 0$ & $1199 \pm 0$ & $233 \pm 0$ & $163 \pm 0$ \\
\hline & 1950 & $505 \pm 2$ & $1338 \pm 2$ & $260 \pm 0$ & $182 \pm 0$ \\
\hline \multirow{4}{*}{$\begin{array}{l}\text { GSFS }(<5 \mathrm{~mm})[161.9 \mathrm{~g}, \\
76.3 \mathrm{~mL}, 110.1 \mathrm{~mm}, 12.7 \mathrm{~s}]\end{array}$} & 10 & $0.4 \pm 0.1$ & $0.9 \pm 0.0$ & $0.1 \pm 0.0$ & $0.3 \pm 0.0$ \\
\hline & 200 & $1.0 \pm 0.0$ & $2.1 \pm 0.0$ & $0.3 \pm 0.0$ & $0.7 \pm 0.0$ \\
\hline & 1000 & $2.0 \pm 0.0$ & $3.7 \pm 0.0$ & $0.6 \pm 0.0$ & $1.2 \pm 0.0$ \\
\hline & 1950 & $12.9 \pm 2.4$ & $6.9 \pm 0.4$ & $1.1 \pm 0.1$ & $2.3 \pm 0.1$ \\
\hline \multirow{4}{*}{$\begin{array}{l}\text { Red soil (Tor St) [109.9 g, } \\
99.0 \mathrm{~mL}, 142.9 \mathrm{~mm}, 16.5 \mathrm{~s} \text { ] }\end{array}$} & 10 & $3.0 \pm 0.9$ & $3 \pm 0$ & $1.6 \pm 0.0$ & $1.7 \pm 0.0$ \\
\hline & 200 & $7.0 \pm 0.1$ & $29 \pm 0$ & $3.6 \pm 0.0$ & $4.0 \pm 0.0$ \\
\hline & 1000 & $12.6 \pm 0.2$ & $45 \pm 0$ & $5.6 \pm 0.0$ & $6.2 \pm 0.0$ \\
\hline & 1950 & $199.9 \pm 9.0$ & $153 \pm 9$ & $18.8 \pm 1.1$ & $20.9 \pm 1.2$ \\
\hline \multirow{4}{*}{$\begin{array}{l}\mathrm{GAC}^{\mathrm{a}}[52.1 \pm 4.0 \mathrm{~g} \\
93.6 \pm 7.1 \mathrm{~mL} \\
135.2 \pm 10.1 \mathrm{~mm} \\
15.5 \pm 1.6 \mathrm{~s}]\end{array}$} & 10 & $3.8 \pm 1.0$ & $2260 \pm 415$ & $4.2 \pm 0.8$ & $2.3 \pm 0.4$ \\
\hline & 200 & $4.5 \pm 0.6$ & $2611 \pm 195$ & $4.8 \pm 0.4$ & $2.7 \pm 0.2$ \\
\hline & 1000 & $5.3 \pm 0.4$ & $2981 \pm 68$ & $5.5 \pm 0.1$ & $3.1 \pm 0.1$ \\
\hline & 1950 & $7.7 \pm 1.4$ & $3225 \pm 204$ & $5.9 \pm 0.4$ & $3.3 \pm 0.2$ \\
\hline \multirow{4}{*}{$\begin{array}{l}\text { Compost [ } 58.9 \mathrm{~g}, 98.7 \mathrm{~mL} \text {, } \\
142.4 \mathrm{~mm}, 16.4 \mathrm{~s}]\end{array}$} & 10 & $0.3 \pm 0.6$ & $17 \pm 0$ & $0.3 \pm 0.0$ & $0.2 \pm 0.0$ \\
\hline & 200 & $1.9 \pm 0.1$ & $121 \pm 2$ & $1.8 \pm 0.0$ & $1.1 \pm 0.0$ \\
\hline & 1000 & $3.4 \pm 0.1$ & $1918 \pm 3$ & $2.8 \pm 0.1$ & $1.7 \pm 0.0$ \\
\hline & 1950 & $6.4 \pm 0.3$ & $226 \pm 7$ & $3.4 \pm 0.1$ & $2.0 \pm 0.1$ \\
\hline \multirow{4}{*}{$\begin{array}{l}\text { Composted feedlot } \\
\text { manure }[70.6 \mathrm{~g}, 95.7 \mathrm{~mL} \text {, } \\
138.1 \mathrm{~mm}, 15.9 \mathrm{~s}]\end{array}$} & 10 & $0.1 \pm 0.1$ & $3 \pm 0$ & $0.0 \pm 0.0$ & $0.0 \pm 0.0$ \\
\hline & 200 & $0.7 \pm 0.0$ & $44 \pm 0$ & $0.6 \pm 0.0$ & $0.4 \pm 0.0$ \\
\hline & 1000 & $1.8 \pm 0.0$ & $94 \pm 1$ & $1.2 \pm 0.0$ & $0.9 \pm 0.0$ \\
\hline & 1950 & $5.1 \pm 0.1$ & $129 \pm 2$ & $1.7 \pm 0.0$ & $1.2 \pm 0.0$ \\
\hline \multirow{4}{*}{$\begin{array}{l}\text { Biochar [18.8 g, } 90.3 \mathrm{~mL} \text {, } \\
130.4 \mathrm{~mm}, 15.1 \mathrm{~s}]\end{array}$} & 10 & $2.1 \pm 0.1$ & $3583 \pm 1$ & $6.5 \pm 0.0$ & $1.3 \pm 0.0$ \\
\hline & 200 & $2.6 \pm 0.1$ & $4352 \pm 15$ & $7.9 \pm 0.0$ & $1.6 \pm 0.0$ \\
\hline & 1000 & $3.3 \pm 0.0$ & $5188 \pm 39$ & $9.4 \pm 0.1$ & $1.9 \pm 0.0$ \\
\hline & 1950 & $5.2 \pm 0.1$ & $5741 \pm 81$ & $10.4 \pm 0.1$ & $2.2 \pm 0.0$ \\
\hline
\end{tabular}

a Mean values for GAC 1, 2 and $3 \pm 95 \%$ confidence intervals.

b $95 \%$ confidence intervals generated by model confidence intervals.
Cumulative sulphur removed (capacity) at the designated elution times 


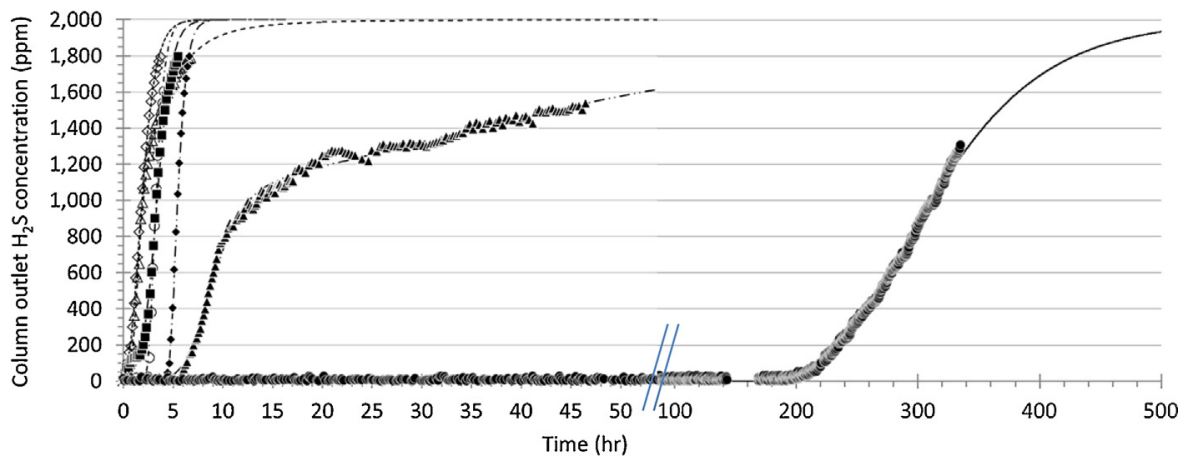

Fig. 3 - Breakthrough curves (column outlet $\mathrm{H}_{2} \mathrm{~S}$ concentrations vs. time) for the tested media. Data are presented for $\mathrm{cg}_{5}(0)$, composted feedlot manure $(\diamond)$, GSFS $(\Delta)$, biochar $(O)$, compost $(\square)$, GAC $(\diamond)$ and Tor Street red soil $(\Delta)$. Note the break in scale/change of scale on the time axes.

expected to be the result of its engineered high porosity and high iron content (Table 1).

The green waste-derived biochar recorded the second highest breakthrough capacity $(6.5 \mathrm{gS} / \mathrm{kg}$ medium). While this value was within the wide range measured by Shang et al. (2012) (1.1-114 g S/kg medium) for camphor derived biochar, it was considerably lower than the capacities reported by Shang et al. (2013) which ranged from 109 to $383 \mathrm{~g} \mathrm{~S} / \mathrm{kg}$ medium for biochars derived from agricultural/forestry wastes products such as camphor, rice hulls and bamboo. Others have reported on engineered GAC which has been impregnated with caustic compounds (Siefers, 2010; Abatzoglou and Boivin, 2009) such as sodium hydroxide $(\mathrm{NaOH})$ or potassium hydroxide $(\mathrm{KOH})$, sodium bicarbonate $\left(\mathrm{NaHCO}_{3}\right)$ and sodium carbonate $\left(\mathrm{Na}_{2} \mathrm{CO}_{3}\right)$ or strong oxidising agents such as potassium permanganate $\left(\mathrm{KMnO}_{4}\right)$. These media then give substantial $\mathrm{H}_{2} \mathrm{~S}$ removal by chemisorption. For example, typical $\mathrm{H}_{2} \mathrm{~S}$ removal capacities for unimpregnated and impregnated activated carbons are 20 and $150 \mathrm{~g} \mathrm{H}_{2} \mathrm{~S} / \mathrm{kg}$ medium, respectively (Abatzoglou and Boivin, 2009). All carbon-based substrates tested during the present study showed a low $\mathrm{H}_{2} \mathrm{~S}$ absorption capacity compared to the iron-based substrates. Comparing the test results of GAC and biochar to literature values (Abatzoglou and Boivin, 2009) indicates that impregnated materials, rather than the neat carbon structure itself, is responsible for the majority of $\mathrm{H}_{2} \mathrm{~S}$ removal under the nearatmospheric test pressures applied in the present study.

Various grades of GSFS were obtained from local suppliers. The GSFS material crushed to a particle size $<5 \mathrm{~mm}$ gave reasonable $\mathrm{H}_{2} \mathrm{~S}$ removal performance (Table 2). In contrast, tests carried out on the M21 coarse GSFS material showed nearinstantaneous breakthrough, most likely due to a low iron content $(<0.1 \%$, Table 1$)$.

While the Tor Street soil was effective at removing $\mathrm{H}_{2} \mathrm{~S}$, both of the Ravensbourne soil samples (which passed $2 \mathrm{~mm}$ and $500 \mu \mathrm{m}$ sieves) showed near instantaneous breakthrough of $\mathrm{H}_{2} \mathrm{~S}$ (low removal capacity). This was despite the fact that the two red soils (Tor Street and Ravensbourne) had similar iron contents and porosity (Table 1, Section 3.1). Overall, these findings suggested that $\mathrm{H}_{2} \mathrm{~S}$ removal capacity of red soils was also influenced by other factors, such as mineralogy (see Section 3.1), rather than simply by iron content, porosity or particle size.

\subsection{Pressure drop}

The results noted above suggested that the Tor Street red soil was a worthwhile candidate for further investigation. Therefore, pressure drop experiments and regeneration exper- iments (next section) were performed on this material (with and without added sugar cane mulch (SCM) as a bulking agent) for comparison with the commercial medium cg5. Fig. 4 presents results of the pressure drop experiments (Section 2.4).

The mean diameter and length of the twenty randomly selected cg5 pellets ( $\pm 95 \%$ CIs) were measured at $3.6 \pm 0.1 \mathrm{~mm}$ and $12.4 \pm 1.3 \mathrm{~mm}$, respectively, resulting in a mean equivalent spherical diameter ( $\left.\bar{x}_{S V}\right)$ of $4.7 \pm 0.1 \mathrm{~mm}$. Given the test column internal diameter of $29.8 \mathrm{~mm}$ (Section 2.2), the resulting column diameter/particle diameter ratio was $6.1 \pm 0.1$. At column diameter/particle diameter ratios less than 10, the Ergun equation may not be applicable due to wall effects (Nemec and Levec, 2005). Consequently, the Ergun equation was not fitted to the pressure drop data for the cg5 medium.

The best fit values for the surface-volume mean diameter $\left(\bar{x}_{S V}\right)$ were found to be 73,62 and $71 \mu \mathrm{m}$ for the red soil, $20 \%$ SCM bulked red soil and 40\% SCM bulked red soil, respectively. The regression fits of Eq. (2) (the Ergun equation) for the red soil and red soil + SCM media are presented in Fig. 4. In this figure, a line has also been fitted to the measured pressure drop data for the cg5 medium. The detailed statistical analysis results are provided in Table S2 of Supplementary material. High $R^{2}$ values $(\geq 0.99)$ indicated that the fits of Eq. (2) were significant and appropriate $(\mathrm{P}<0.05)$. At a particular flow velocity, the pressure drop was substantially higher (about 10 times) through the red soil than through the $\mathrm{cg}_{5}$

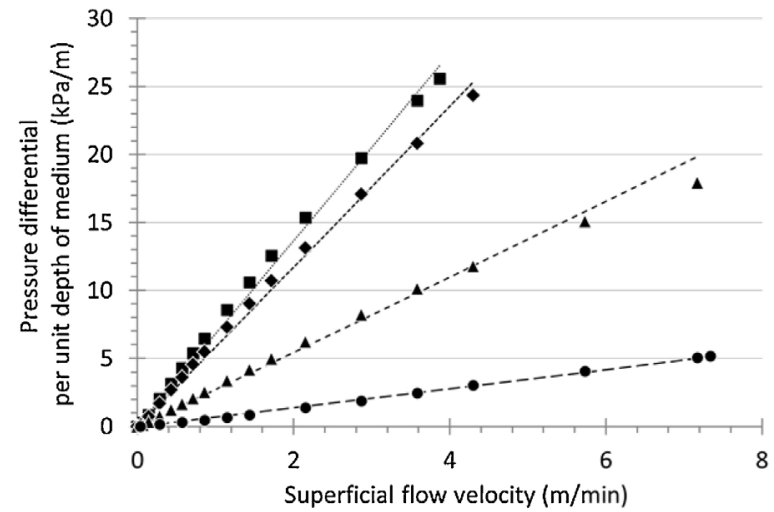

Fig. 4 - Pressure drop per unit depth of the red soil ( $\square$ ), red soil bulked with $20 \%$ SCM v/v ( $(\downarrow)$, red soil bulked with $40 \%$ SCM v/v $(\Delta)$ and $\operatorname{cg}_{5}(0)$ media, measured in the test column. Lines are regression fits with the Ergun equation (Eq. (2)) over a range of $\mathrm{N}_{2}$ flow velocities (with the exception of the line plotted for the red soil medium which was fitted to the measured data). 


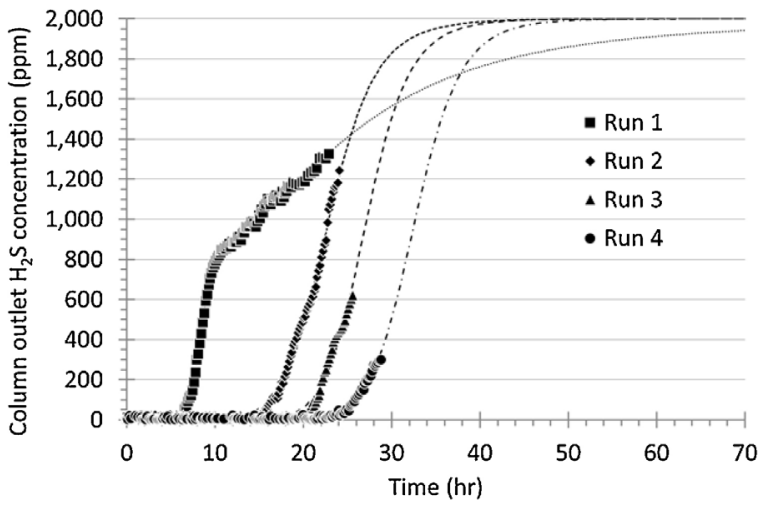

Fig. 5 - Breakthrough curves for a red soil (Tor St) sample tested in consecutive media regeneration trials.

commercial medium. The relatively low pressure drop of the $\mathrm{Cg}_{5}$ medium is reflective of its engineered characteristics (Section 3.1). It is anticipated that these laboratory results would be scalable, and could provide predictions of pressure drop in full-scale installations. These results indicate that a relatively high upstream pressure would be required with the red soil media, consuming substantially more energy than with the $\mathrm{cg}_{5}$ medium, and starkly increasing the risk of tunnelling and uneven migration of the biogas through the packed column, which could lead to inferior $\mathrm{H}_{2} \mathrm{~S}$ removal. Bulking with $40 \%$ SCM decreased the pressure drop by $50 \%$ compared to red soil only, substantially reducing energy costs but would obviously require a larger vessel for similar $\mathrm{H}_{2} \mathrm{~S}$ removal performance in the field.

\subsection{Media regeneration}

Fig. 5 presents breakthrough curves for a red soil sample (Tor Street, Toowoomba) tested in consecutive media regeneration trials (Runs 1-4, Section 2.5). Table S2 in Supplementary material gives the corresponding $\mathrm{H}_{2} \mathrm{~S}$ removal capacities. The results suggested that the $\mathrm{H}_{2} \mathrm{~S}$ removal performance of the medium (at least for removal up to breakthrough) improved with regeneration, which was somewhat unexpected because the use-regenerate-reuse of an iron-based medium can lead to a progressive loss in capacity due to the build-up of elemental sulphur (Wang et al., 2011). It is possible that mechanical disturbance or chemical alternation by reactive regeneration of sulphide and iron into oxidised forms could have exposed previously inaccessible reactive surface area in the soil structure (and thus additional active ingredient) and/or decreased diffusion limitations by increasing pore size. However, these hypotheses require further testing in future works.

\subsection{Applications}

Our laboratory results suggested that the volumetric $\mathrm{S}$ adsorption capacity of the cg5 commercial medium, at breakthrough, was approximately 8-59 times that of the Tor Street red soil (Tables S1 and S2, respectively). Consequently, the medium replacement interval for a cg5 column would be 8-59 times longer than for a red soil column with a similar volumetric capacity (Section 3.2). At certain locations where suitable krasnozem or red ferrosol soils are available at a piggery site, or within close proximity, the supply cost of the red soil may be negligible. However, the availability and low supply cost would need to be weighed up against increased labour costs for more frequent medium replacement, because of the lower
$\mathrm{H}_{2} \mathrm{~S}$ removal capacity of red soil (Section 3.2). In this work, only two red soil samples were tested, as obtained from a local area. There would be other naturally occurring red soils with different (and perhaps superior) $\mathrm{H}_{2} \mathrm{~S}$ removal capacities.

Increasing $\mathrm{H}_{2} \mathrm{~S}$ removal capacities observed in four successive regeneration trials with red soil (Section 3.4) appeared to be favourable, suggesting that regeneration, on-site at a piggery, could extend the life of red soil filter media. Such regeneration may be done inside the adsorption column by passing a small quantity of air through the column in bypass mode, or by removing the media from the column and spreading it on a hard surface to be exposed to air for conversion back into a useable form. Future work could explore such regeneration options.

In comparison to the commercial cg5 medium, the relatively high pressure drop through the red soil (Section 3.3) would require the installation of a higher pressure blower driven by a more powerful motor consuming more energy. While the addition of the ground SCM bulking agent to the red soil substantially reduced the pressure drop (and energy consumption) at the expense of reduced $\mathrm{H}_{2} \mathrm{~S}$ adsorption capacity, the SCM may be prone to combustion during the exothermic regeneration process. Further in-field testing could assess the structural stability of the SCM following extended exposure to biogas saturated with moisture. The use of alternative heat and moisture resistant bulking agents may address such issues.

Alternative filter media, such as the red soil, could provide treatment as a secondary polishing step to ensure biogas quality. Technologies for biological removal of hydrogen sulphide are now increasingly being considered, because of their high efficiency and low operating costs compared with physio-chemical biogas cleaning (Abatzoglou and Boivin, 2009; Weiland, 2010). Such a biological scrubber could reduce $\mathrm{H}_{2} \mathrm{~S}$ concentrations from $2000-3000 \mathrm{ppm}$ down to $50-100 \mathrm{ppm}$ (Hagen et al., 2001), therefore placing a much lower load on any subsequent polishing step. Under such conditions, medium replacement intervals could be substantially extended and column capacities limited to manageable and cost effective dimensions. Such would produce biogas highly suitable for use in internal combustion engines, and could greatly improve the safety of on-farm biogas systems, noting that biogas combustion devices are often located in close proximity to pig sheds.

\section{Conclusion}

In this laboratory-scale study, the performance of several commercial and alternative $\mathrm{H}_{2} \mathrm{~S}$ sorption media was evaluated. Conclusions from this study can be summarised as follows:

- A superior performance of the commercial medium (cg $\mathrm{cg}_{5}$ pellets) reflected its engineered high porosity and high iron content.

- All carbon based materials, including GAC and biochar, showed poor $\mathrm{H}_{2} \mathrm{~S}$ removal, indicating that pure physisorption is not so important at low pressures such as in typical on-farm biogas installations.

- A red soil was the most promising alternative medium (2-12 g S/kg medium at breakthrough).

- The crystalline structure of the iron-oxide minerals in red soil appeared to strongly influence its $\mathrm{H}_{2} \mathrm{~S}$ removal capacity.

- Pressure drop was generally high with the red soils (10 times that of the commercial $\mathrm{cg}_{5}$ pellets) but could be effectively 
reduced with a bulking agent, albeit at a loss of active treatment volume.

- An unexpected increase in $\mathrm{H}_{2} \mathrm{~S}$ sorption capacity was observed with regeneration of used red soil media in air, perhaps due to mechanical disruption or chemical reaction.

In summary, certain red soils appeared to be promising alternative $\mathrm{H}_{2} \mathrm{~S}$ sorption media. Full-scale trials are currently underway with particular interest in the possible future use of a simple red-soil adsorption column, especially as a polishing step after an initial treatment by a biological scrubber to remove most of the $\mathrm{H}_{2} \mathrm{~S}$ from the biogas.

\section{Acknowledgements}

This research was conducted under Pork CRC Project No. 4C-104 'Low-cost options for biogas energy use on-farm at piggeries'. We acknowledge funding support for this research from the Pork CRC, the Queensland Government (Department of Agriculture and Fisheries) and the University of Queensland. We acknowledge the contributions of Mr Lei Ge, School of Chemical Engineering, University of Queensland, for conducting the Helium Pycnometry analyses, Dr David Mayer (DAF) for assistance with statistical analyses and Ms Tracy Longhurst (DAF) for laboratory analyses of materials.

\section{Appendix A. Supplementary data}

Supplementary data associated with this article can be found, in the online version, at http://dx.doi.org/10.1016/j.psep.2016.11.001.

\section{References}

Allan, A., 2012. Review of Biogas Cleaning-Final Report to Meat \& Livestock Australia Limited, Project Code: A.ENV.0098, Prepared by GHD Pty Ltd. Meat \& Livestock Australia Limited, North Sydney, NSW.

Abatzoglou, N., Boivin, S., 2009. A review of biogas purification processes. Biofuels Bioprod. Biorefin. 3 (1), 42-71.

ACP Technologies Inc, 2012. Brochure: Clean-gas cg cg $_{5}$ Dry $\mathrm{H}_{2} \mathrm{~S}$ Removal System. Distributed exclusively in North America. Univar Inc., Commerce, CA 90040 , http://www.acp-cg.com/documents/cg4\%205\%20Univar \%20brochure\%202012.pdf. (Accessed 11 November 2015).

Cherosky, P., Li, Y., 2013. Hydrogen sulfide removal from biogas by bio-based iron sponge. Biosyst. Eng. 114, 55-59.

Elias, A., Barona, A., Arreguy, A., Rios, J., Aranguiz, I., Penas, J., 2002. Evaluation of a packing material for the biodegradation of $\mathrm{H}_{2} \mathrm{~S}$ and product analysis. Process Biochem. 37, 813-820.

Ergun, S., 1952. Fluid flow through packed columns. Chem. Eng. Prog. 48 (2), 89-94.

FNR, 2005. Ergebnesse des Biogas-Messprogramms-Results of the Biogas Monitoring Program. Technical Monitoring Report. FNR, Guezlow, Germany.

Greenberg, A.E., Clesceri, L.S., Eaton, A.D., 1992. Standard Methods for the Examination of Water and Wastewater. American Public Health Association, Washington DC

Hagen, M., Polman, E., Jensen, J., Myken, A., Jönsson, O., Dahl, A., 2001. Danish Gas Technology Centre. In: Haynes, W.M. (Ed.), CRC Handbook of Chemistry and Physics. , 96th Edition. CRC Press/Taylor \& Francis, Boca Raton, FL (Internet Version 2016).

Haynes, W.M. (Editor-in-Chief), 2016. CRC Handbook of Chemistry \& Physics Online, 96th edition.

http://www.hbcponline.com.ezproxy.library.uq.edu.au/. (Accessed 14 March 2016).
Heubeck, S., Craggs, R.J., 2010. Biogas recovery from a temperate climate covered anaerobic pond. Water Sci. Technol. 61 (4), 1019-1026.

Isbell, R.F., 1996. The Australian Soil Classification. CSIRO Publishing, Collingwood, Vic 3066.

Ko, T.H., 2008. Removal of hydrogen sulphur from coal derived gas by iron oxides in various oxisols. Environ. Eng. Sci. 25, 969-973.

Ko, T.H., 2011. Application of Zn-contaminated soil: feasibility study on the removal of $\mathrm{H}_{2} \mathrm{~S}$ from hot coal derived gas. Environ. Chem. Lett. 9, 77-82.

Ko, T.H., Hsueh, H.T., 2012. Removal of hydrogen sulphide by iron-rich soil: application of the deactivation kinetic model for fitting breakthrough curve. Aerosol Air Qual. Res. 12, 1355-1361, http://dx.doi.org/10.4209/aaqr.2012.03.0060.

Loeppert, R.H., Inskeep, W.P., 1996. Iron. In: Methods of Soil Analysis-Part 3, Chemical Methods. Soil Science Society of America Inc. and American Society of Agronomy Inc., Madison, Wisconsin, USA (Chapter 23).

Nemec, D., Levec, J., 2005. Flow through packed bed reactors: 1. Single-phase flow. Chem. Eng. Sci. 60, 6947-6957.

Ryckebosch, E., Drouillon, M., Vervaeren, H., 2011. Techniques for transformation of biogas to biomethane. Biomass Bioenergy 35, 1633-1645.

Safe Work Australia Workplace, 2013. Exposure Standards for Airborne Contaminants (ISBN 978-1-74361-055-8). http://www.safeworkaustralia.gov.au/sites/SWA/about /Publications/Documents/772/Workplace-exposure-standards -airborne-contaminants.pdf. (Accessed 11 November 2015).

Safley, L.M., Westerman, P.W., 1988. Biogas production from anaerobic lagoons. Biol. Wastes 23, 181-193.

Schwertmann, U., Cornell, R.M., 2000. Iron Oxides in the Laboratory, Preparation and Characterisation, 2nd edition. Wiley-VCH, Weinheim, Federal Republic of Germany, http://dx.doi.org/10.1002/9783527613229.

Shang, G., Shen, G., Liu, L., Chen, Q., Xu, Z., 2013. Kinetics and mechanisms of hydrogen sulphide adsorption by biochars. Bioresour. Technol. 133, 495-499.

Shang, G., Shen, G., Wang, T., Chen, Q., 2012. Effectiveness and mechanisms of hydrogen sulfide adsorption by camphor-derived biochar. J. Air Waste Manage. Assoc. 62 (8), 873-879, http://dx.doi.org/10.1080/10962247.2012.686441.

Siefers, A.M., 2010. A Novel and Cost-effective Hydrogen Sulfide Removal Technology Using Tire Derived Rubber Particles. Graduate Theses and Dissertations. Paper 11281. Iowa State University.

Skerman, A., Pech, L., Faile, D., Brown, G., 2015. Options for Cost-effective and Efficient Use of Piggery Biogas Energy. Report prepared for the Co-operative Research Centre for High Integrity Australian Pork, http://porkcrc.com.au/wp-content/uploads/2015/09/4C-114 -Final-Report.pdf. (Accessed 18 January 2016).

Stace, H.C.T., Hubble, G.D., Brewer, R., Northcote, K.H., Sleeman, J.R., Mulcahy, M.J., Hallsworth, E.G., 1968. A Handbook of Australian Soils. Rellim Technical Publications, Glenside, South Australia.

Wang, D.M., 2008. Breakthrough Behaviour of $\mathrm{H}_{2} \mathrm{~S}$ Removal with an Iron Oxide Based CG-4 Adsorbent in a Fixed-Bed Reactor. Master of Science Thesis. University of Saskatchewan, Saskatoon, SK, Canada.

Wang, H., Fang, D., Chuang, K.T., 2008. A sulfur removal and disposal process through $\mathrm{H}_{2} \mathrm{~S}$ adsorption and regeneration: ammonia leaching regeneration. Process Saf. Environ. Prot. 86, 296-302.

Wang, H., Wang, D.M., Chuang, K.T., 2011. A sulphur removal and disposal process through $\mathrm{H}_{2} \mathrm{~S}$ adsorption and regeneration: breakthrough behaviour investigation. Process Saf. Environ. Prot. 89, 53-60.

Weiland, P., 2010. Biogas production: current state and perspectives-mini-review. Appl. Microbiol. Biotechnol. 85, 849-860, http://dx.doi.org/10.1007/s00253-009-2246-7.

Wellinger, A., Lindberg, A., 2005. Biogas Upgrading and Utilization-IEA Bioenergy Task 24: Energy from Biological 
Conversion of Organic Wastes. International Energy Association, Paris, France.

Wiebe, A., 2014. The Benefits of Biogas Conditioning. Biorem Technologies Inc,

http://www.biorem.biz/wp-content/uploads/2014/02/The -Benefits-of-Biogas-Conditioning.pdf. (Accessed 21 January 2016).

Wiedemann, S.G., McGahan, E.J., Murphy, C.M., 2012. Energy, Water and Greenhouse Gas Emissions in Australian Pork Supply Chains: A Life Cycle Assessment. Report prepared for the Pork CRC. FSA Consulting, Toowoomba, Queensland.
Willis, S., 2015. Toowoomba Pig Focus Group Data, 12 Months ending Sep 2015. Department of Agriculture and Fisheries, Toowoomba, Queensland.

Zicari, S.M., 2003. Removal of Hydrogen Sulphide from Biogas Using Cow-manure Compost. A Thesis presented to the Faculty of the Graduate School of Cornell University in Partial Fulfilment of the Requirements for the Degree of Master of Science,

http://www.green-trust.org/Al\%20Rutan/MS-Thesis-Steve -Zicari.pdf. (Accessed 21 January 2016). 